Word count: 5,939

\title{
Use of lignin biopolymer from industrial waste as bitumen extender for asphalt mixtures

\author{
I. Pérez ${ }^{a}$, A.R. Pasandin ${ }^{a, *}$, Jorge C. Pais ${ }^{b}$, Paulo A.A. Pereira ${ }^{b}$
} \\ ${ }^{a}$ Universidade da Coruña, E. T. S. I. Caminos, Canales y Puertos, Campus de Elviña s/n, 15071. A Coruña, Spain \\ ${ }^{b}$ Universidade do Minho, Escola de Engenharia, 4800-058 Guimarães, Portugal \\ * Corresponding author. Tel.: +34-981167000. Fax: +34-981167170
}

E-mail addresses: iperez@udc.es (I.Pérez), arodriguezpa@udc.es (A.R.Pasandín), jpais@civil.unminho.pt (J.C.Pais),ppereira@civil.uminho.pt (P.A.A. Pereira).

\begin{abstract}
Liquid waste containing lignin, a biopolymer of vegetable origin, is generated from the production of wood hardboards. Because polymers improve the performance of asphalt mixtures, this work studies the possibility of using this industrial waste as a bitumen extender in the production of asphalt mixtures. Thus, asphalt mixtures with $0 \%$ (control), 5\%, 10\%, 20\%, and $40 \%$ of industrial waste were produced. The bitumen-aggregate adhesion, moisture damage resistance, resilient modulus, permanent deformation resistance, and thermal susceptibility of such mixtures were analysed. Asphalt mixtures with $20 \%$ of industrial waste have shown the best moisture damage resistance. As the percentage of industrial waste increased, the thermal susceptibility of the mixture also increased. Therefore, it can be stated that it is appropriate to use this industrial waste containing lignin as a bitumen extender. It can be used in asphalt mixtures for road pavement, mainly by substituting $20 \%$ of the bitumen by this liquid waste. It reduces the consumption of bitumen and improves the performance of asphalt mixtures, contributing to the purpose of sustainable construction. The industrial waste was not subjected to any transformation process, thus facilitating its use. The reduction in the use of bitumen in asphalt mixtures by adding this industrial waste contributes to the goals of sustainable development and cleaner production of asphalt mixtures.
\end{abstract}

Keywords: lignin; biopolymer; industrial waste; asphalt mixtures; bitumen extender 


\section{Introduction}

Polymers are widely used as bitumen modifiers as it has been demonstrated that they can improve the performance of asphalt mixtures. Thus, asphalt mixtures made with polymermodified bitumen have better rutting performance at high temperatures, higher fatigue resistance, and higher cracking resistance at low temperatures as a consequence of a noticeable reduction in their thermal susceptibility (Brovelli et al., 2015, Ait-Kadi et al., 1996; Hernández et al., 2014). In addition, environmental benefits are associated with the use of modified bitumens owing to the increase in their lifecycle (Vila-Cortavitarte et al., 2018, Brovelli et al., 2014, Brovelli et al., 2013).

Biopolymers, also known as 'green polymers' (Hernández et al., 2014), are organic polymers synthesized by microorganisms, plants, trees, and other biological organisms (Chang et al., 2016). Furthermore, the polymers chemically synthesised from vegetable oils, resins, sugars, and other biological sources could be included in this definition (Hernández et al., 2014). Biopolymers are produced from renewable resources (Chang et al., 2016), which makes them environmentally friendly.

Moreover, biopolymers are harmless and can easily be found in nature (Hataf et al., 2018). In fact, biopolymers can be obtained from several available raw materials (Chang et al., 2016). Lignin is the second most abundant biopolymer on Earth after cellulose (Boerjan et al., 2003), and it is present in all vascular plants (Chávez-Sifontes and Domine, 2013) binding the fibres in wood (Boerjan et al., 2003).

Part of the vegetal biomass containing lignin can be considered as a waste material, which is mainly obtained from the wood, paper, and biofuel industries (Batista et al., 2018) or even from agricultural processes (Chavez-Sifontes and Domine, 2013). Depending on the biomass source and as a consequence of the industrial process used to obtain wood hardboards, paper, etc., various types of lignin with different properties can be obtained. According to the industrial process used, the most common kinds of lignin are the sulphite, kraft, and soda lignin, followed by the organosolv lignin (Chávez-Sifontes and Domine, 2013).

The high abundance of lignin, its cementitious nature, and the fact that lignin and asphalt have some similar chemical compounds, the carbon-rings (aromatics) (Hernández et al., 2014), make this biopolymer particularly interesting for manufacturing asphalt mixtures. 
The problem associated with the real overexploitation and limited crude oil resources (Sun et al., 2017) can be mitigated by the use of lignin as a partial substitute of bitumen. Additionally, the use of lignin in bitumen is beneficial for the reduction of $\mathrm{CO}_{2}$ emissions (van Vliet et al., 2016), because it does not generate any additional $\mathrm{CO}_{2}$.

Thus, the use of lignin in the manufacture of asphalt mixtures can contribute to the goals of sustainable construction and cleaner production.

Some attempts to use lignin in the production of asphalt mixtures have been reported.

The Federal Highway Administration (FHWA) carried out a study in which the possibility of using wood lignin as a substitute for bitumen and as a bitumen extender in hot and cold asphalt mixtures was analysed (Terrel et al., 1980). As a result, the wood lignin showed promising results as an extender, but not as a bitumen substitute. Nevertheless, this study also concluded that, at that moment, the use of lignin as bitumen extender was not economically feasible.

Sundstrom et al. (1983) stated that asphalt mixtures made with $30 \%$ of lignin by weight of bitumen reached the maximum Marshal stability at $6 \%$ of binder content.

Williams (2008) used four lignin-containing co-products as bitumen antioxidant, obtaining an improvement of the high temperature properties and a worsening of the low temperature properties of the bitumen. The bioasphalt was derived from lignin-rich corn stover waste. In 2010, a trial bike path was constructed in Iowa replacing $3 \%$ of its bitumen by this bioasphalt. The bike path showed adequate performance (Bourzac, 2015).

Pan (2012) stated that lignin could be used as antioxidant for bitumen. However, the lignin temperature must be controlled to avoid lignin aging.

In 2015 (Gosselink, 2016; Wageningen University \& Research, 2015), the first test section worldwide was made using bioasphalt from lignin in Zeeland (the Netherlands). The lignin was chemically transformed using fast pyrolysis. The bioasphalt was made by using $50 \%$ of lignin. The trial section, $70 \mathrm{~m}$ in length, was made with low temperature bioasphalt. After two years, the performance of the road was adequate. Following the same research line, a bicycle path was constructed in 2017 using eight types of lignin. 
Xu et al. (2017) demonstrated that lignin-modified bitumen improves the rutting performance at high temperatures and aging resistance of asphalt mixtures. On the contrary, their fatigue life could be reduced.

Xie et al. (2017) also demonstrated that Kraft lignin could be used as bitumen modifier, leading to asphalt mixtures with better performance at high temperature.

Boomika et al. (2017) used plastic and lignin as partial bitumen substitutes. The authors stated that the use of $15 \%$ of lignin and $20 \%$ of plastic produced efficient results.

Batista et al. (2018) stated that lignin modified bitumen significantly improves the thermal cracking resistance of asphalt mixtures at temperatures as low as $-12{ }^{\circ} \mathrm{C}$.

In another research conducted by The Netherlands Organization for Applied Scientific Research (TNO) (Bourzac, 2015; Slaghek et al., 2017; van Vliet et al., 2016), some chemical modifications were made to lignin. As a result, a more hydrophobic lignin was achieved. This modified lignin was blended with bitumen (up to $25 \%$ by weight of bitumen). The obtained bitumen presented high resistance to climatic conditions with greater service life. Nevertheless, this bitumen is more expensive than conventional bitumen.

It is interesting to note that most researchers do not use directly lignin waste in bitumen modification for road applications because the untreated lignin does not mix with bitumen (Hernández et al., 2014; Bourzac, 2015).

Other biopolymers have been used in the bitumen industry, such as xantan gum ( $\mathrm{Tu}$ et al., 2016a), welan gum (Tu et al., 2016b), and starch (Al-Hadidy et al., 2011), but their characteristics make them less suitable than lignin for road pavement applications.

\section{Aims and scope}

In the present study, industrial waste containing a vegetal lignin biopolymer is used for partial substitution of the bitumen in asphalt mixtures.

Industrial waste from the manufacture of wood hardboards will be used without any transformation, i.e., it will be mixed directly with conventional bitumen. Different percentages of bitumen substitution by industrial waste will be tested, namely, $0 \%$ (control mix), $5 \%, 10 \%$, $20 \%$, and $40 \%$ by bitumen weight.

The obtained binder (bitumen + industrial waste) was used to produce AC 22 bin G asphalt mixtures and produce laboratory specimens for testing. The volumetric and mechanical 
properties of the specimens (indirect tensile strength, water sensitivity, resilient modulus, thermal susceptibility, and permanent deformation resistance) will be analysed.

This work analyses the use of this waste as a partial substitute for bitumen, as a bitumen extender, for application in asphalt mixtures, and the improvement in performance of these asphalt mixtures is also studied.

This work contributes to the purposes of sustainable construction and cleaner production, as industrial waste rich in raw materials will be utilised, without the need for subsequent transformations or production of leftover waste materials.

\section{Materials and methods}

\subsection{Aggregates}

A local contractor supplied the aggregates used in this work for the manufacture of asphalt mixtures. The material is Hornfels from a Galician (Spain) quarry (figure 1).

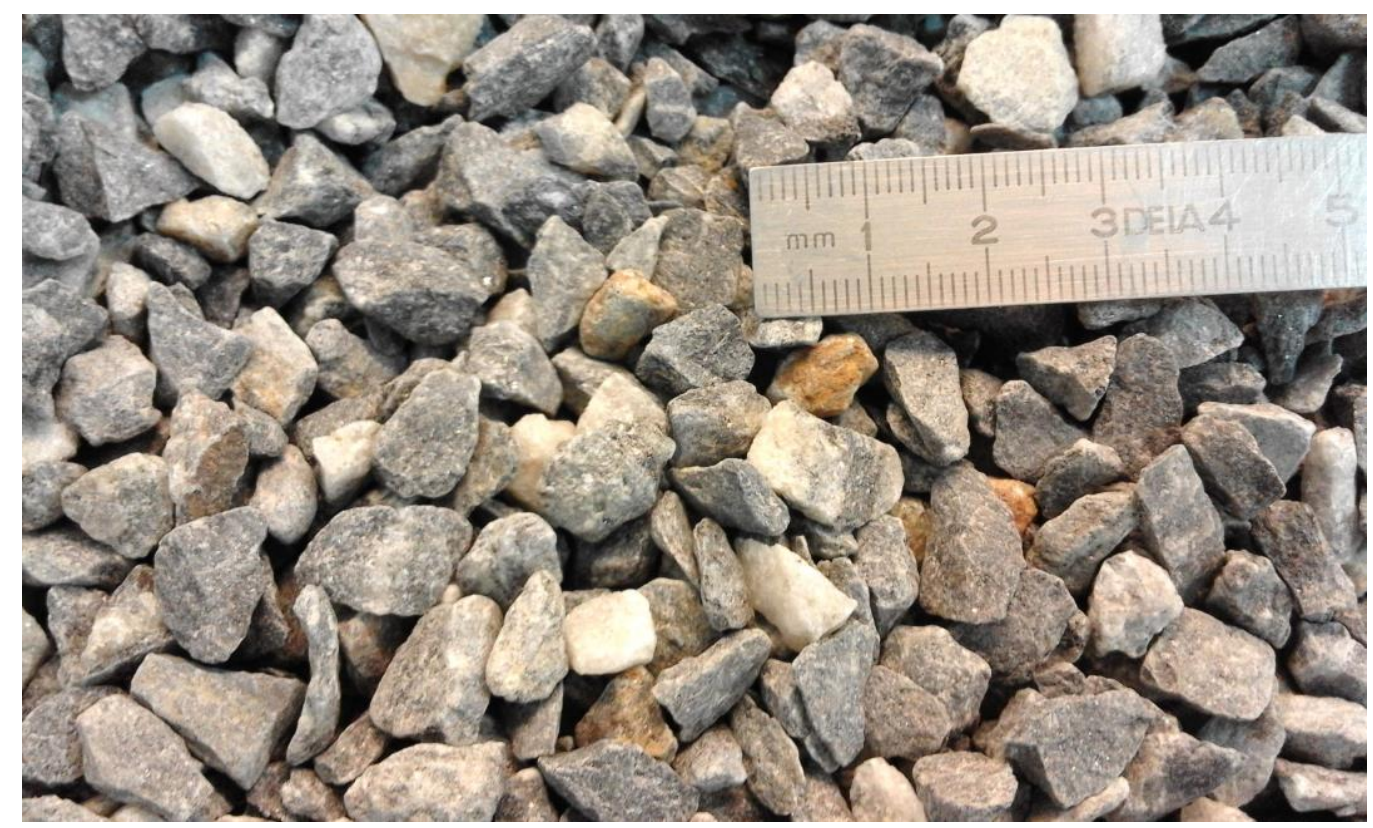

Figure 1. Fraction $4 / 8 \mathrm{~mm}$ of the Hornfels used in this work

It is expected that these aggregates present a poor water resistance because of its mineralogical composition, which is rich in silica $\left(62.30 \%\right.$ of $\left.\mathrm{SiO}_{2}\right)$. 
The main properties of the aggregates were analysed according to the Spanish General Technical Specifications for Roads, also known as PG-3 (MFOM, 2015). As can be observed in Table 1, the sand equivalent (SE) complies with the PG-3 for all the traffic categories, and the Los Angeles (LA) abrasion coefficient.

Table 1. Aggregate characterization

\begin{tabular}{|c|c|c|c|c|c|}
\hline \multirow[t]{2}{*}{ Property } & \multirow[t]{2}{*}{ Standard } & \multirow[t]{2}{*}{ Hornfels } & \multicolumn{3}{|c|}{ PG-3 Specifications (*) } \\
\hline & & & T00-T1 & $\mathrm{T} 3-\mathrm{T} 2$ & $\mathrm{~T} 4$ \\
\hline $\mathrm{SE}(\%)$ & EN 933-8 (AENOR, 2012) & 61 & $\geq 50$ & $\geq 50$ & $\geq 50$ \\
\hline LA abrasion $(\%)$ & EN 1097-2 (AENOR, 2010) & 14.1 & $\leq 25$ & $\leq 30$ & - \\
\hline $\begin{array}{l}\left.{ }^{*}\right) \text { Traffic category T00 } \\
\text { Traffic category T0 refer } \\
\text { Traffic category T1 refer } \\
\text { Traffic category T2 refer } \\
\text { Traffic category T3 refer } \\
\text { Traffic category T4 refer }\end{array}$ & $\begin{array}{l}\text { fers to AADHT (Annual Average Daily } \\
\text { o } 4,000>\text { AADHT } \geq 2,000 \\
\text { o } 2,000>\text { AADHT } \geq 800 \\
\text { o } 800>\text { AADHT } \geq 200 \\
\text { o } 200>\text { AADHT } \geq 50 \\
\text { o AADHT }<50\end{array}$ & vy Traffic) $\geq$ & & & \\
\hline
\end{tabular}

\subsection{Bitumen}

A 50/70 penetration grade bitumen was chosen to prepare the asphalt mixtures. The bitumen has a penetration of $66 \times 0.1 \mathrm{~mm}$ at $25^{\circ} \mathrm{C}$ and a softening point of $48{ }^{\circ} \mathrm{C}$.

\subsection{Industrial waste containing lignin}

The industrial waste used as bitumen extender is a $100 \%$ natural product. It is a concentrate of wood extracts, mainly from eucalyptus, from the manufacture of hard fibres boards. As shown in figure 2 , the industrial waste is a brown liquid with a faint odour of caramel. Its main properties are listed in Table 2. 


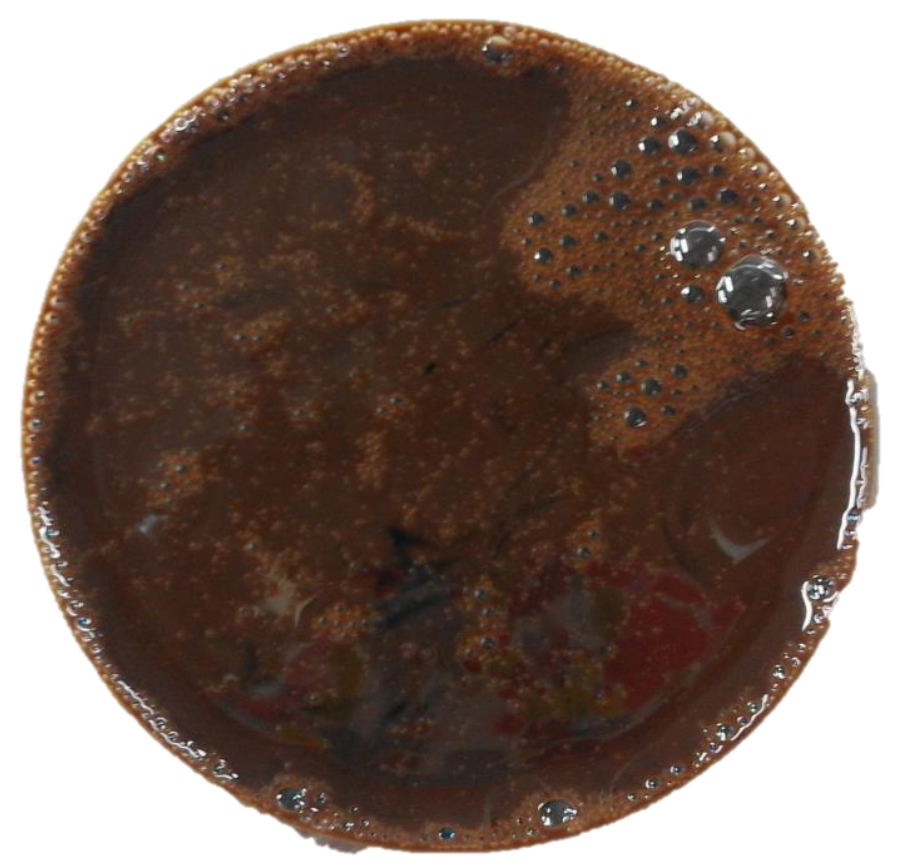

Figure 2. Industrial waste containing lignin used in this work

Table 2. Main properties of the industrial waste containing lignin

\begin{tabular}{ll}
\hline Property & Value \\
\hline $\mathrm{pH}$ & 3.2 \\
Densitity at $75^{\circ} \mathrm{C}\left(\mathrm{kg} / \mathrm{m}^{3}\right)$ & 1,155 \\
Viscosity at $80^{\circ} \mathrm{C}(\mathrm{mPa} . \mathrm{s})$ & 14 \\
Total solids $(\mathrm{g} / \mathrm{L})$ & 444 \\
Volatile solids $(\mathrm{g} / \mathrm{L})$ & 385 \\
Sulphates $(\mathrm{mg} / \mathrm{g})$ & 8 \\
Aluminium $(\mathrm{Al})(\mathrm{mg} / \mathrm{L})$ & 8,197 \\
Calcium $(\mathrm{Ca})(\mathrm{mg} / \mathrm{L})$ & 4,600 \\
Magnesium $(\mathrm{Mg})(\mathrm{mg} / \mathrm{L})$ & 5,500 \\
Sodium $(\mathrm{Na})(\mathrm{mg} / \mathrm{L})$ & 4,725 \\
Silicon $(\mathrm{mg} / \mathrm{g})$ & $<3$ \\
Vanadium $(\mathrm{mg} / \mathrm{kg})$ & $<0.5$ \\
Chlorine $(\mathrm{mg} / \mathrm{kg})$ & 6,500 \\
\hline
\end{tabular}

The industrial waste has $43.69 \%$ of dry matter. This means that $100-43.69=56.31 \%$ is water. The main components of this dry matter are $41.46 \%$ of sugar (mainly xylose, glucose, galactose, rhamnose, arabinose, and mannose), $23.39 \%$ of lignin (16.29\% of insoluble Klason lignin and $7.10 \%$ of soluble lignin), $13.3 \%$ of pectin, $11.8 \%$ of polyphenols, $9.05 \%$ of mineral matter, and other compounds that appear in low percentages. The high sugar content explains the caramellike odour, which is particularly noticeable when the compound is heated with the bitumen. 
In this work, the industrial waste was added to the hot bitumen $\left(170{ }^{\circ} \mathrm{C}\right)$ in percentages of $0 \%$ (control), 5\%, 10\%, 20\%, and 40\% and manually blended. Furthermore, a percentage of $60 \%$ of industrial waste was added to determine the volumetric properties and stripping potential; however, the poor results obtained caused this percentage to be discarded before the end of the research.

\subsection{Asphalt mixture}

For this research, the AC 22 base G asphalt mixture for road-pavement base course was chosen. The aggregate gradation limits given by the PG-3 (MFOM, 2015) and the selected aggregate grading curve are shown in figure 3.

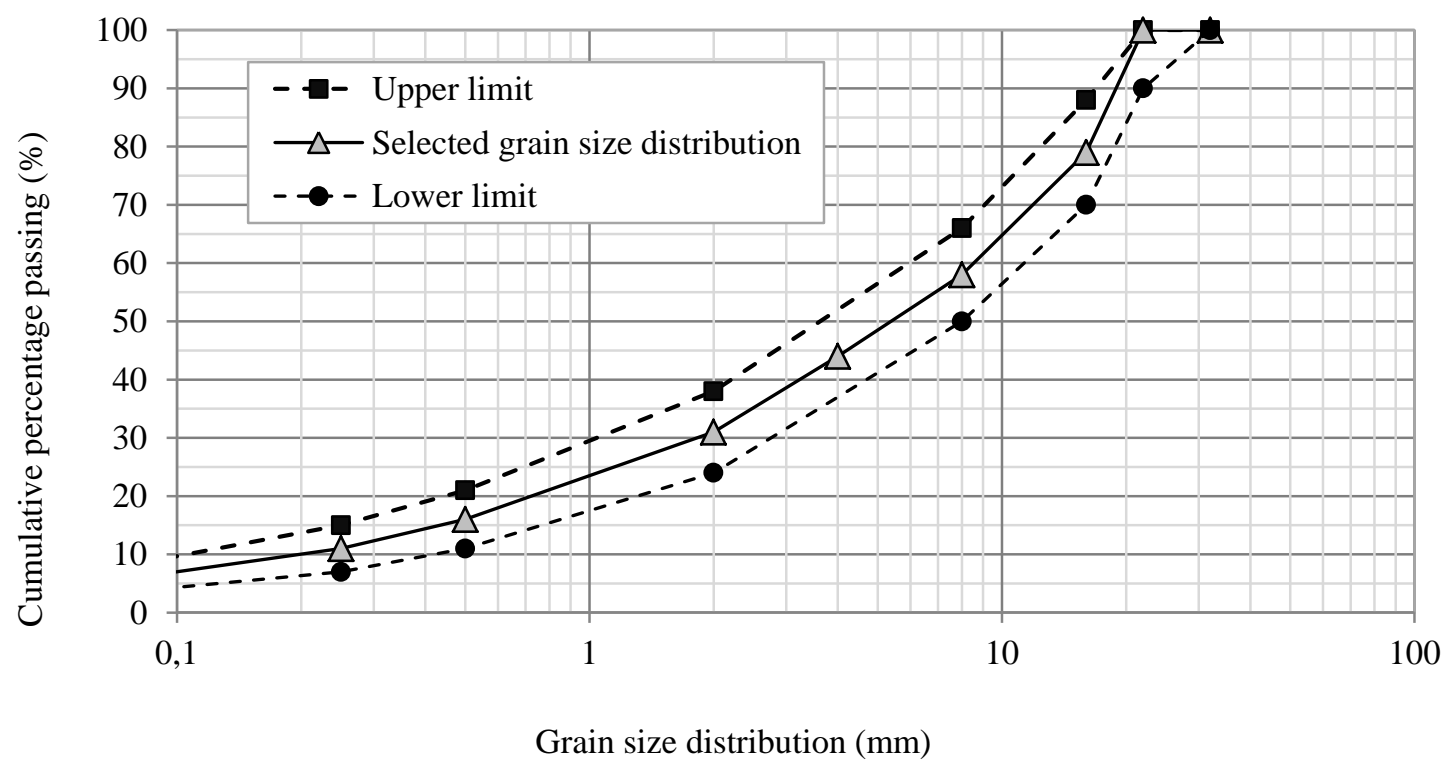

Figure 3. Aggregate gradation curve and standard limits

\subsection{Volumetric properties}

For the volumetric characterization of the asphalt mixtures, the air voids were determined following UNE-EN 12697-8 (AENOR, 2003) by using the following equation:

$V a=\frac{\rho_{m}-\rho_{b}}{\rho_{m}} \times 100$

where $\rho b=$ bulk specific density and $\rho m=$ maximum specific density. 
The bulk specific density by saturated surface dry (SSD) was determined on cylindrical Marshall specimens compacted with 75 blows per face according to UNE-EN 12.697-6 (AENOR, 2012c).

The maximum specific density was determined on loose asphalt mixtures according to UNE-EN 12.697-5 (AENOR, 2010b).

According to the PG-3, the minimum bitumen content of the AC 22 base G is 3.9\%. Percentages of $3.9 \%, 4.1 \%, 4.3 \%$, and $4.5 \%$ of binder were used in this work.

\subsection{Bitumen and aggregate adhesion}

Two qualitative tests, namely the boiling water test and the rolling bottle test have been carried out to analyse whether the incorporation of industrial waste containing lignin improves the adhesion between the aggregate and the binder. Both tests were carried out on loose asphalt mixtures.

\subsubsection{Boiling Water Test}

The boiling water test has been carried out in accordance with ASTM D3625-96 (2005). In this test, a sample of loose asphalt mixture is introduced in boiling water for $10 \mathrm{~min}$. Afterwards, the bitumen that remains in the water is removed using a towel. Then, the asphalt mixture is removed from the water and dried. The percentage of the aggregate surface that continues coated is visually estimated.

It is not easy to establish a criterion that indicates the suitability of asphalt mixtures in terms of moisture damage resistance (Solaimanian et al., 2003). In the case of the boiling water test, Kennedy et al. (1984) indicate that based on the correlation between tests conducted on the laboratory and field performance, asphalt mixtures that retained less than $70 \%$ of the bitumen on the aggregate surface are moisture susceptible. Kim and Coree (2005) indicate that this percentage must be $95 \%$. In any case, results over this percentage cannot guarantee a good field performance owing to other factors contributing to moisture damage resistance (Solaimanian et al., 2003). Thus, this test is useful for initial screening of the asphalt mixtures (Brown et al., 2001) and for identifying problematic materials (Jorgensen, 2002).

\subsubsection{Rolling Bottle Method}


The rolling bottle test has been carried out in accordance with the UNE-EN 12697-11 (AENOR, 2012) standard. In this test, a sample of loose asphalt mixture is introduced into a bottle containing distilled water and allowed to rotate for $6 \mathrm{~h}$ and for $24 \mathrm{~h}$. At the end of these two rotation periods, the percentage of aggregate surface that remains coated with bitumen is visually estimated by two operators.

There are no requirements on the percentage of aggregate surface that should be coated with bitumen after the rotation periods. Therefore, this test is useful for comparison between mixtures produced with different proportions of industrial waste. Particularly, this test is used to analyse the affinity between bitumen and aggregate, strength of the adhesion, and stripping resistance (Solaimanian et al., 2003).

\subsection{Moisture damage resistance}

To evaluate the water sensitivity of the asphalt mixtures made with $0 \%, 5 \%, 10 \%, 20 \%$, and $40 \%$ of industrial waste as bitumen extender, the indirect tensile test was conducted as specified in UNE-EN 12697-12 (AENOR, 2009). This standard indicates that eight cylindrical specimens, compacted with 50 blows per face in the Marshall hammer, must be tested for each binder content.

Four samples will constitute the 'dry set', while the other four will constitute the 'wet set'. The samples of the 'dry set' were kept at room temperature, while the samples of the 'wet set' were saturated in a water bath for 3 days at $40{ }^{\circ} \mathrm{C}$. Then, both sets were left for a minimum of $2 \mathrm{~h}$ at $15^{\circ} \mathrm{C}$ with the 'dry set' in air and the 'wet set' in water. After this period of time, the tensile strength ratio (TSR) was determined as follows:

$\mathrm{TSR}=\frac{\operatorname{ITS}_{\mathrm{w}}}{\operatorname{ITS}_{\mathrm{D}}} \times 100$

where $\mathrm{TSR}=$ the tensile strength ratio $(\%), \mathrm{ITS}_{\mathrm{W}}=$ the average tensile strength of the 'wet set' $(\mathrm{MPa})$, and $\mathrm{ITS}_{\mathrm{D}}=$ the average tensile strength of the 'dry set' $(\mathrm{MPa})$.

The PG-3 (MFOM, 2015) requires a TSR $\geq 80 \%$ to accept an AC 22 base $\mathrm{G}$ in terms of moisture damage resistance.

\subsection{Resilient modulus and thermal susceptibility}


The resilient modulus of the asphalt mixtures was calculated following the Annex C of UNEEN 12697-26 (AENOR, 2012). In this test, compressive repeated haversine loads were applied in a vertical diametral plane of cylindrical specimens compacted with 75 blows per face with the Marshall hammer. The repetition period of the impulse is $3 \pm 0.1 \mathrm{~s}$ and the rise time is $124 \pm 4 \mathrm{~ms}$. The maximum load must lead to a maximum horizontal strain of $0.005 \%$ of the specimen diameter. In this test, 10 conditioning pulse cycles were followed by 5 load pulse cycles. Then, the resilient modulus is determined as follows:

$M_{R}=\frac{F \times(v+0,27)}{z \times h}$

where $M R=$ resilient modulus $(\mathrm{MPa}), \mathrm{F}=$ maximum applied load $(\mathrm{N}), \mathrm{z}=$ horizontal deformation (mm), h=sample thickness $(\mathrm{mm})$, and $v=$ =Poisson's ratio (assuming a Poisson's ratio of 0.35 for the different temperatures according to UNE-EN 12697-26 (AENOR, 2012).

The test was conducted at different service temperatures with the purpose of analysing the influence of the industrial waste on the thermal susceptibility of the mixtures.

The thermal susceptibility may be defined as the resistance of the binder to change its resilient modulus and viscosity with temperature (Cong et al., 2012). The lower temperature dependence the asphalt mixture has, the less thermal susceptible the binder is (Cong et al., 2012).

In order to avoid problems of non-linearity, the temperatures have been chosen below $40{ }^{\circ} \mathrm{C}$. Particularly, the samples have been tested at temperatures of $2{ }^{\circ} \mathrm{C}, 10^{\circ} \mathrm{C}, 20^{\circ} \mathrm{C}$, and $30^{\circ} \mathrm{C}$.

Furthermore, the mixtures have been tested after an initial curing time of 14 to 42 days (as stated in the standard) and before a period of 6 months with the aim of analysing the effect of ageing time in the thermal susceptibility.

\subsection{Permanent deformation resistance}

A repeated load axial test without confinement was conducted in order to evaluate the resistance to permanent deformation. The Cooper NU 14 tester machine was used to conduct this test. The British Standard DD 226:1996 (BSi, 1996) describes this test as follows: each cylindrical Marshall specimen must be held at $30{ }^{\circ} \mathrm{C}$ in a climate chamber for a minimum of $4 \mathrm{~h}$, and then 
preloaded for $600 \pm 6 \mathrm{~s}$ at $10 \mathrm{kPa}$ of axial stress with the load platens. After this time, each specimen was subjected to 1,800 load cycles. In order to simulate loading in the field, square repeated load pulses were selected. The width pulse and the rest period were of $1 \mathrm{~s}$, while the stress level was of $100 \pm 2 \mathrm{kPa}$.

The axial permanent strain was calculated as follows:

$\varepsilon_{d(n, T)}=\frac{\Delta h}{h_{0}} \times 100$

where $\varepsilon_{\mathrm{d}(\mathrm{n}, \mathrm{T})}=$ the axial permanent strain (\%) after $\mathrm{n}$ load applications at temperature $\mathrm{T}$ in ${ }^{\circ} \mathrm{C}$, $\Delta \mathrm{h}=$ the axial permanent deformation $(\mathrm{mm})$, and $\mathrm{h}_{0}=$ the initial distance between the two load platens (mm).

A group of specimens has been tested just after it was manufactured, whereas the other group of specimens was tested after a period of 6 months with the aim of analysing the effect of ageing time in the permanent deformation resistance.

\section{Results and Discussion}

\subsection{Volumetric properties}

Figure 4 shows the air void content (Va) versus binder content of the asphalt mixtures, for each industrial waste percentage. This figure also shows the Va limits required by the PG-3. 


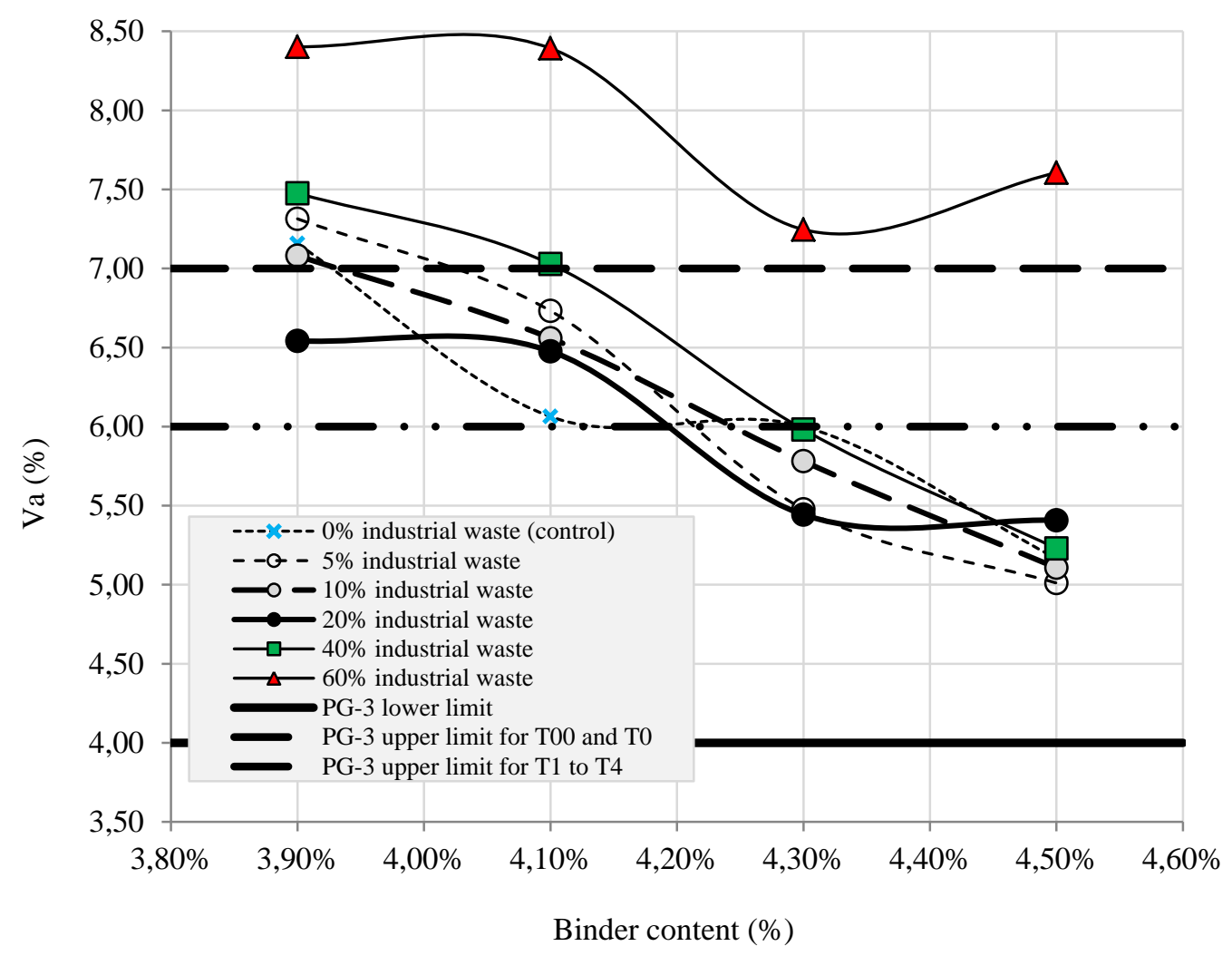

Figure 4. Air void content versus bitumen content for different percentages of industrial waste

The results presented in figure 4 show that the Va decreases as the binder content increase, but mixtures made with $60 \%$ of industrial waste show an irregular behaviour. Probably, the high water content introduced in the mixture is mainly responsible for this performance.

Figure 4 shows that there is not a clear trend between $\mathrm{Va}$ and industrial waste content. Nevertheless, mixtures made with $40 \%$ of industrial waste generally present a Va higher than that of mixtures made with lower waste percentages. This trend is even clearer when analysing the asphalt mixtures made with $60 \%$ of industrial waste. In this case, $\mathrm{Va}$ is much higher than the one obtained for mixtures with $0 \%$ to $40 \%$ of waste. Clearly, when a very high amount of industrial waste is used, the compaction is more difficult. Thus, it must be said that some crystallized particles can be appreciated at first sight when $40 \%$ and $60 \%$ of industrial waste were used. When $20 \%$ or less waste is used, this phenomenon is not appreciated. Probably, when higher amounts of waste are used, some coalescence tend to occur, leading to these crystallised particles, and thus, to a heterogeneous structure. This could also explain the irregular performance of mixtures made with bitumen blended with $60 \%$ of industrial waste.

Moreover, as observed in figure 4, mixtures made with $0 \%$ (control mixture), 5\%, 10\%, 20\%, and $40 \%$ of industrial waste containing lignin biopolymer and with $4.30 \%$ and $4.50 \%$ of binder 
content comply with the PG-3 for all the heavy traffic categories. Mixtures made with $0 \%, 5 \%$, and $10 \%$ of industrial waste and binder content of $4.10 \%$ comply with the PG-3 for T1 to T4 heavy traffic categories. The same occurs with mixtures made with $20 \%$ of industrial waste and $3.90 \%$ and $4.10 \%$ of binder content. Mixtures made with $60 \%$ of industrial waste do not comply with the PG-3 for any of the heavy traffic categories.

It is interesting to note that when industrial waste is blended with bitumen, some foaming occurs owing to the sudden warming of the water included in this waste. As the industrial waste percentage increases, the foaming is more pronounced in such a way that for $40 \%$ and $60 \%$ of industrial waste, it is difficult to operate the blend owing to the high foam formation. This fact can be observed in figure 5 , which shows $20 \%$ of industrial waste blended with bitumen. At the beginning (figure 5a), the bitumen shows its usual appearance, but after a few seconds (figure $5 b$ ), foaming leads to bubble formation inside the bitumen, which is clearly noticeable in its surface. Moreover, a high volume expansion of the bitumen is produced when foaming occurs. The arrows included in figure 5 show this increase in volume.

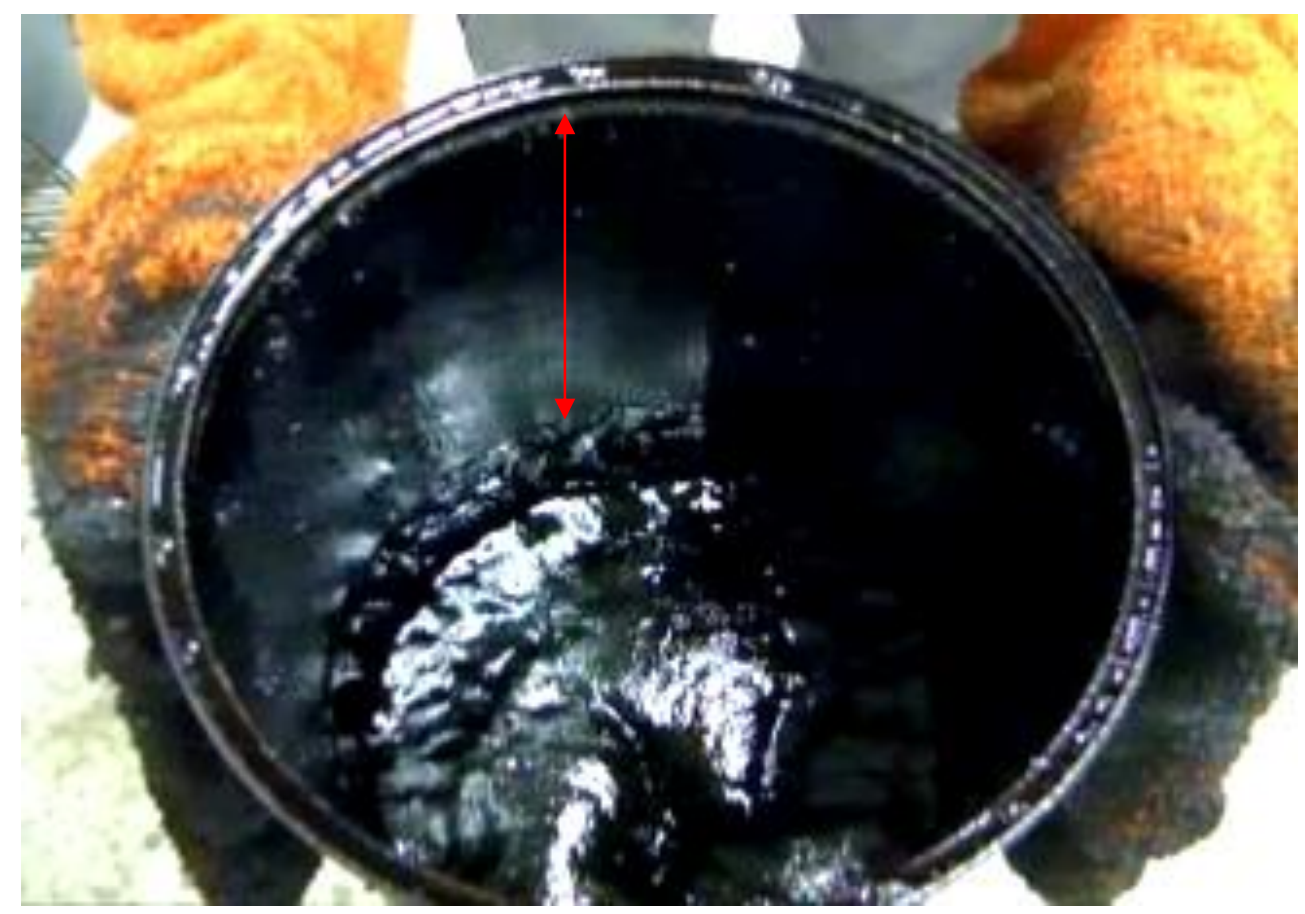




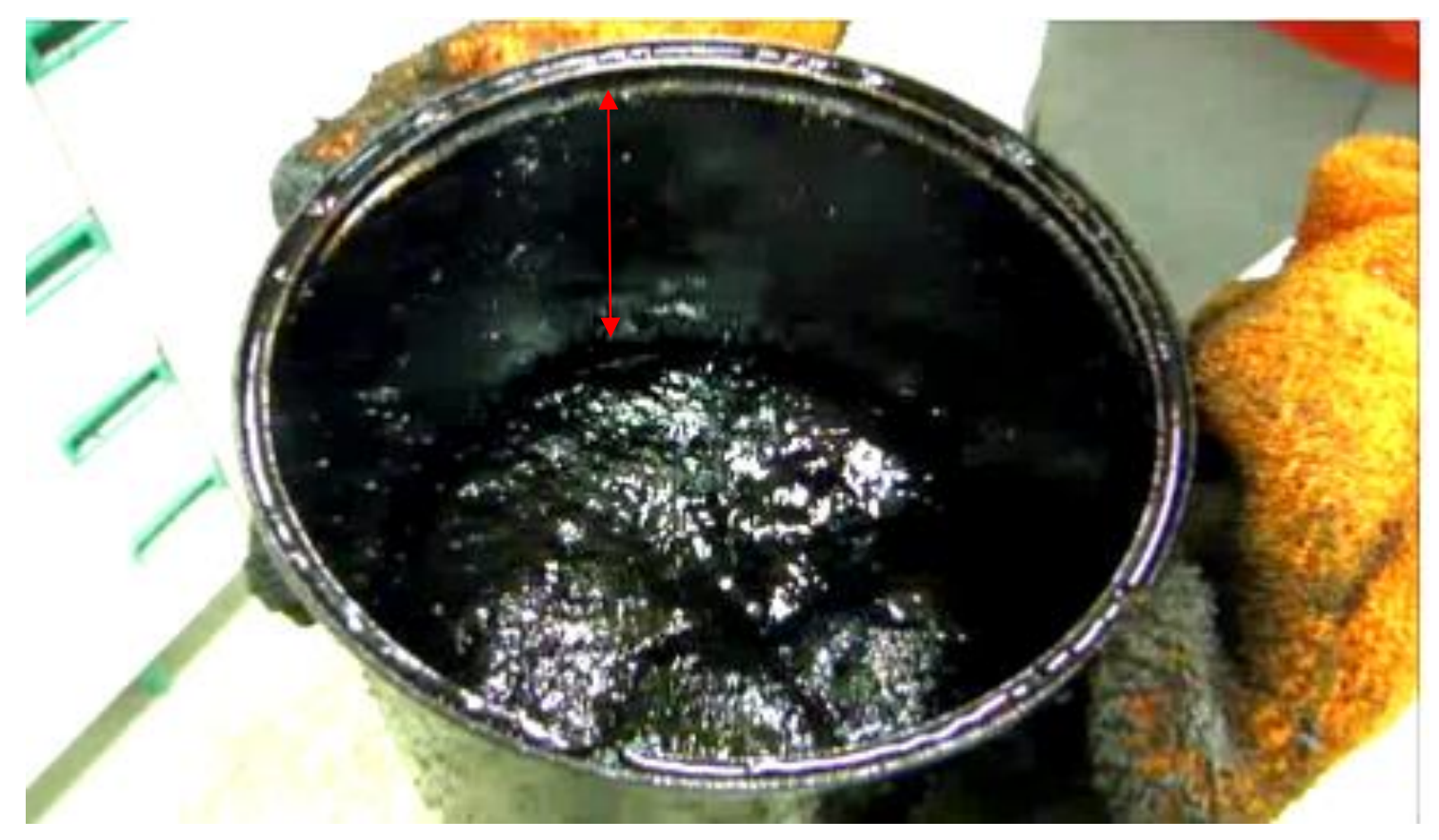

Figure 5. Bitumen with $20 \%$ of industrial waste: a) at the beginning of the mixing process and b) after $5 \mathrm{~s}$ of the beginning of the mixing process

The irregular behaviour of the mixtures made with $60 \%$ of industrial waste, together with the large $\mathrm{Va}$ and the difficulty in using the binder made with bitumen and $60 \%$ of waste, caused these mixtures to be discarded.

\subsection{Bitumen and aggregate adhesion}

Figure 6 shows the percentage of aggregate surface that remains coated after $24 \mathrm{~h}$ of rolling time in the rolling bottle test and after $24 \mathrm{~h}$ of drying time in the boiling water test. 


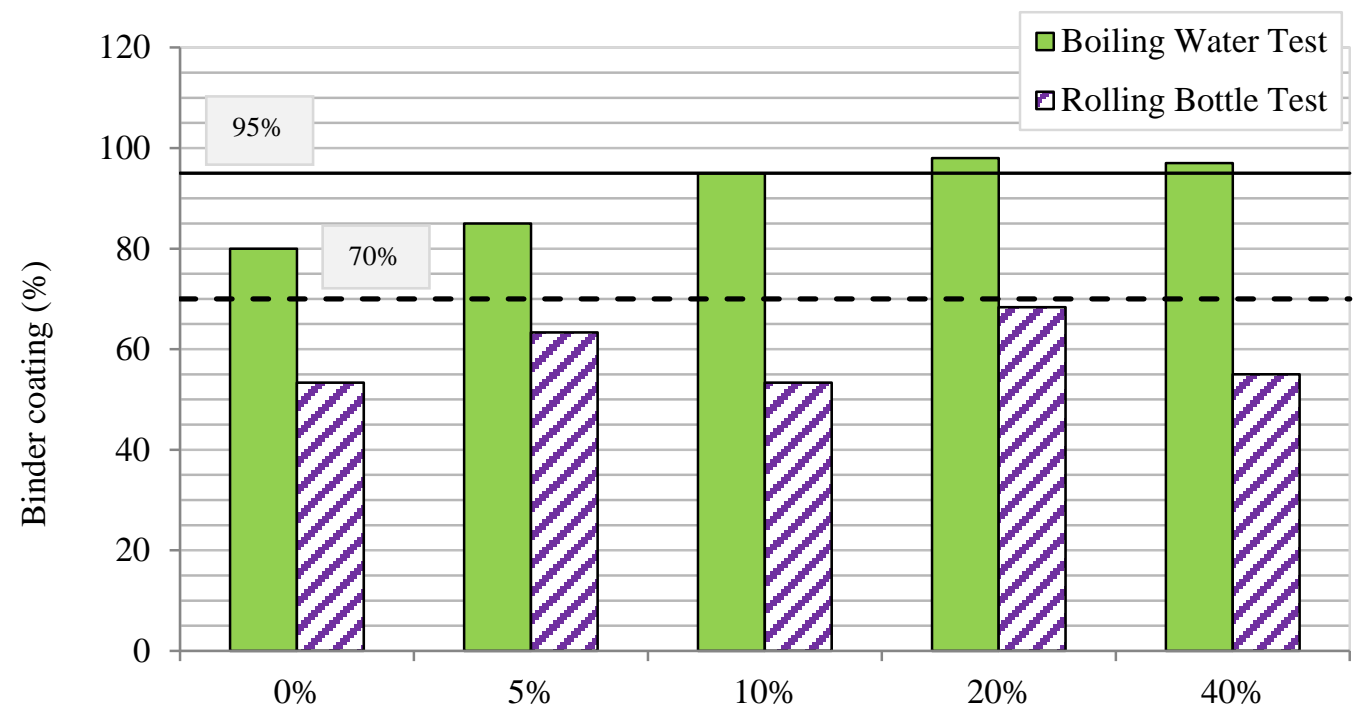

Industrial waste containing lignin biopolymer $(\%)$

Figure 6. Bitumen-aggregate adhesion results after $24 \mathrm{~h}$

Figure 6 shows that all tested mixtures lead to boiling water test results over $70 \%$, which is the minimum required by some researchers to accept the material. However, only the mixtures made with $10 \%$ to $40 \%$ of industrial waste lead to boiling water test results over $95 \%$, which is the minimum required by other researchers.

Both tests show that the best binder coating always occurs for mixtures with $20 \%$ of industrial waste. In general, for industrial waste percentages of $0 \%$ to $20 \%$, as the industrial waste percentage increases, the percentage of aggregate surface that remains coated with the binder also increases. The only exception of this trend is the result of the rolling bottle test for the blend with $10 \%$ of industrial waste, which is clearly due to the typical dispersions of these tests. When the highest amount of industrial waste is used (40\%), the coated surface is reduced. As said before, the high water content and the formation of crystallised particles could also explain this performance.

Therefore, the use of industrial waste containing lignin biopolymer as extender improves the affinity between bitumen and aggregate when using percentages up to $20 \%$. As said before, higher percentages introduce high water amounts and lead to the formation of crystallised particles. Both seem to affect the affinity between aggregates and binder. At lower percentages, the effect of the lignin included in the industrial waste and the foaming effect of the water lead to better affinity between the aggregates and the binder. It is possible that the foam formation as a consequence of the industrial-waste water evaporation improves the aggregate-binder mixing, thus improving the aggregate-bitumen adhesion. 
Nevertheless, the water sensitivity of the mixture is conditioned by factors different from the binder-aggregate affinity. In this regard, it is necessary to analyse the water resistance of the asphalt mixtures on compacted specimens, as described in the following section.

\subsection{Moisture damage resistance}

Figure 7 shows the TSR versus binder content for mixtures made with $0 \%, 5 \%, 10 \%, 20 \%$, and $40 \%$ of industrial waste containing lignin.

For mixtures made with $0 \%$ of industrial waste (control mixture), only $4.5 \%$ of binder content achieves the minimum TSR of $80 \%$, required by the PG-3 for AC 22 base G. Thus, the optimum binder content for the control mixture is $4.5 \%$. This binder content leads to mixtures that can be used in all heavy traffic categories, as said in section 3.1.

For mixtures made with $5 \%, 10 \%$, and $40 \%$ of industrial waste, none of the tested binder contents led to mixtures with adequate water sensitivity.

The mixture made with $20 \%$ of industrial waste achieved the minimum TSR with $4.1 \%$ of binder content. Thus, the optimum binder content for this mixture is $4.1 \%$. This bitumen percentage leads to mixtures that can be used in heavy traffic categories $\mathrm{T} 1$ to $\mathrm{T} 4$, as said in section 3.1 .

It means that using a $20 \%$ of industrial waste as bitumen extender requires less bitumen content than the control mixture to achieve an adequate water resistance. Nevertheless, the mixtures should be used for heavy traffic categories T1 to T4 (medium and low traffic roads). 


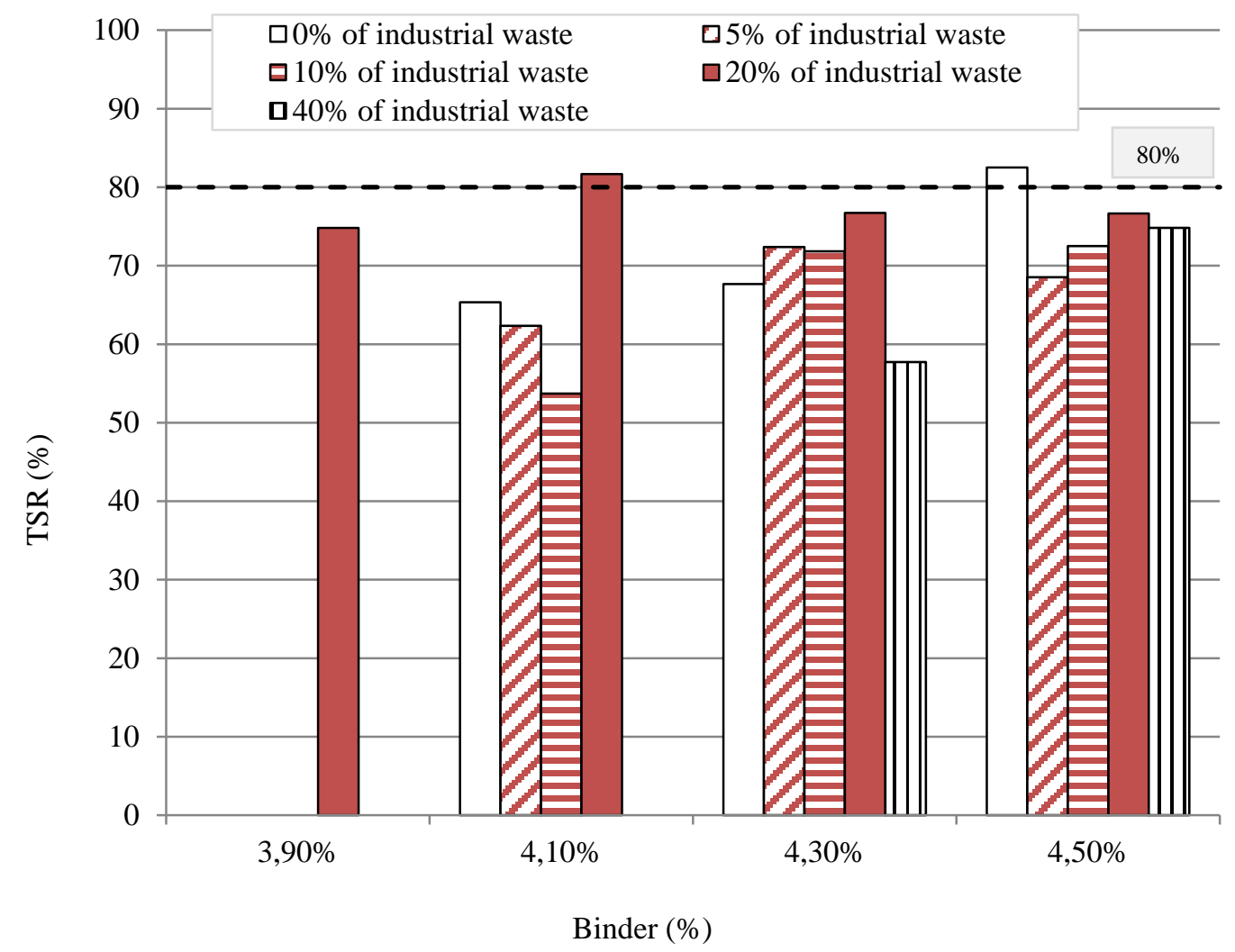

Figure 7. TSR vs binder content for mixtures with $0 \%, 5 \%, 10 \%, 20 \%$, and $40 \%$ of industrial waste

Figure 8 shows the indirect tensile strength of the dry and wet sets for mixtures made with $0 \%$, $5 \%, 10 \%, 20 \%$, and $40 \%$ of industrial waste containing lignin. This figure clearly shows that mixtures made with $20 \%$ of industrial waste present dry (figure $8 \mathrm{a}$ ) and wet (figure $8 \mathrm{~b}$ ) indirect tensile strengths higher than the control mixture, for all the tested binder contents.

It is possible to observe that mixtures made with $20 \%$ of industrial waste at their optimum bitumen content (4.1\%) display higher dry indirect tensile strength than the control mixture at its optimum bitumen content (4.5\%). Regarding the wet indirect tensile strength, for mixtures made with $20 \%$ of industrial waste it is slightly lower, but very similar. Thus, there is not a loss of indirect tensile strength when using $20 \%$ of industrial waste at the optimum bitumen content. 


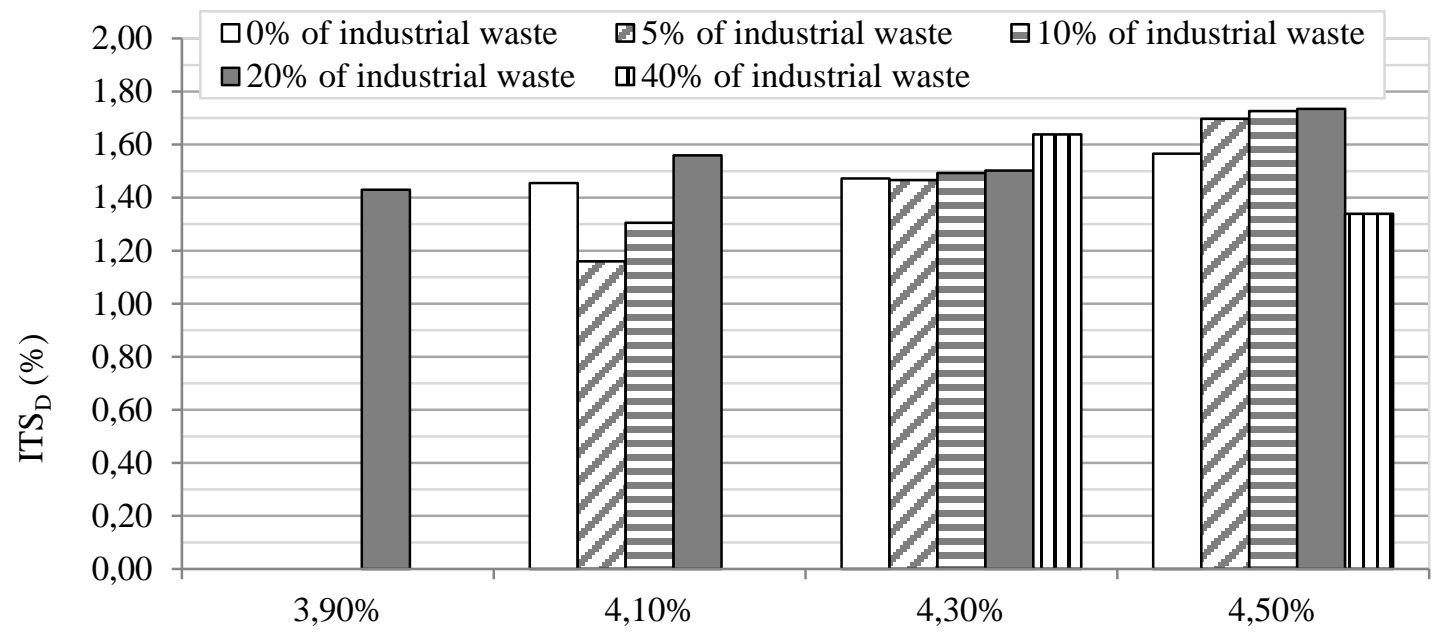

a) 'dry set' $\quad$ Binder (\%)

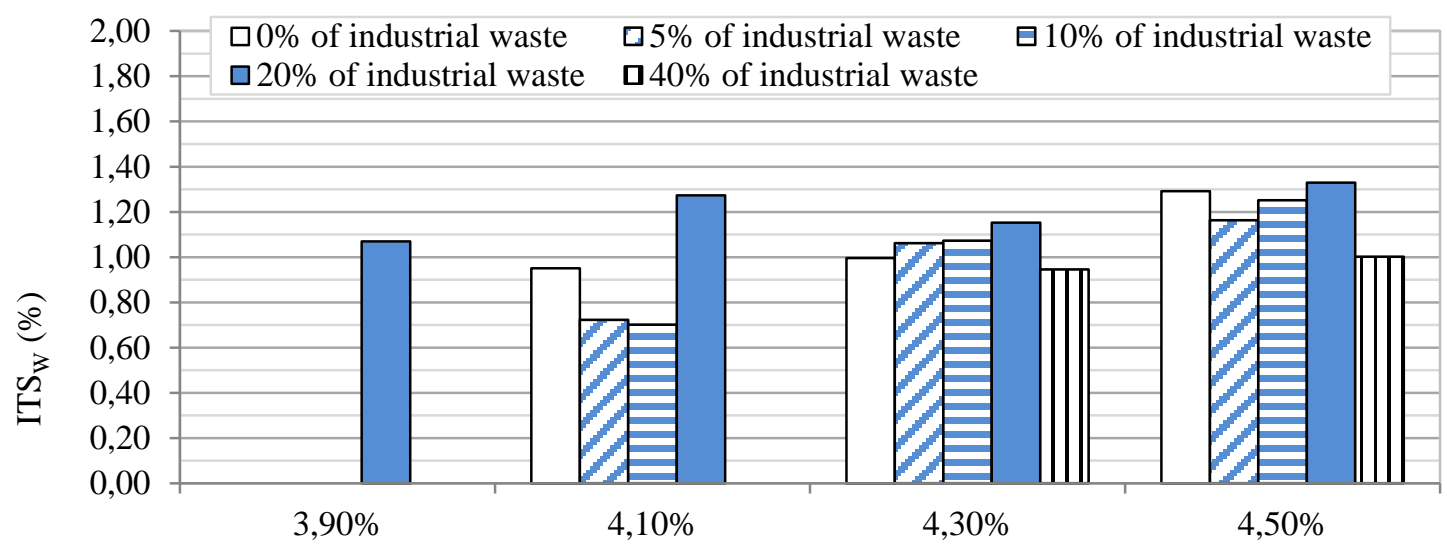

b) 'wet set'

Binder (\%)

Figure 8. Indirect tensile strength versus binder content for mixtures made with $0 \%, 5 \%, 10 \%$, $20 \%$, and $40 \%$ of industrial waste: a) 'dry set' and b) 'wet set'

These results allow to state that the percentage of $20 \%$ of industrial waste as bitumen extender seems to be the most adequate for the production of asphalt mixtures. It improves the affinity between the aggregate and the binder and reduces bitumen consumption in terms of water sensitivity for low and medium traffic roads.

Industrial waste percentages of $10 \%$ or less seem not to have enough lignin to appreciate its effect on the asphalt mixtures. In these cases, the negative effect of the water content appears to be more noticeable than the effect of the lignin. In contrast, industrial waste percentages of $40 \%$ or more introduce heterogeneities in the asphalt mixtures owing to their high water content and lead to the formation of crystallised particles that negatively affect the performance of the asphalt mixtures. Thus, $20 \%$ is the optimum amount of industrial waste containing lignin biopolymer. 


\subsection{Resilient modulus and thermal susceptibility}

Figure 9 shows the resilient modulus for an AC 22 base G made without industrial waste at its optimum bitumen content (4.5\%) and for an AC 22 base G made with $20 \%$ of industrial waste, also at its optimum bitumen content (4.1\%). The resilient modulus was obtained at $2{ }^{\circ} \mathrm{C}, 10{ }^{\circ} \mathrm{C}$, $20^{\circ} \mathrm{C}$, and $30^{\circ} \mathrm{C}$.

Figure 9 clearly shows that as the temperature increases, the resilient modulus decreases owing to the thermoplastic nature of the binder.

In figure $9 \mathrm{a}$, the differences between the control mixture and that with $20 \%$ of industrial waste can be appreciated. Clearly, at low temperatures, the resilient modulus of the control mixture is higher than that of the mixture made with $20 \%$ of industrial waste. The opposite occurs at the highest temperatures. Thus, the thermal susceptibility of the mixtures made with $20 \%$ of industrial waste is lower than that of the control mixture.

Low thermal susceptibility controls permanent deformation at high temperatures and avoids fracture at low temperatures (Zapién-Castillo et al., 2016). Thus, the performance of the asphalt mixture made with $20 \%$ of industrial waste will be higher, leading to higher fatigue resistance at low temperatures and higher resistance to permanent deformation at high temperatures. 

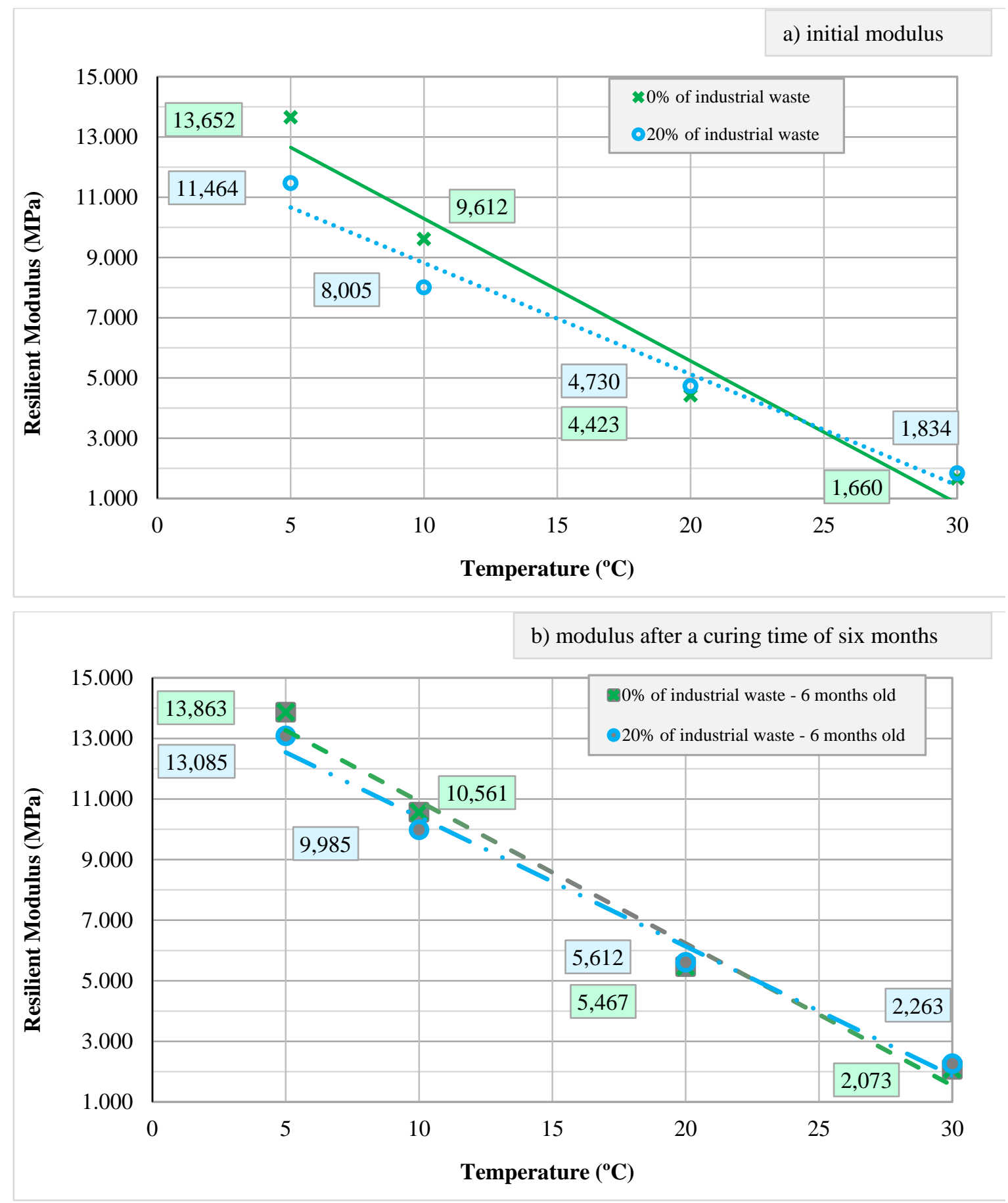

Figure 9. Resilient modulus at different temperatures: a) initial modulus and b) modulus after a curing time of six months

Figure $9 \mathrm{~b}$ also confirms this conclusion. Asphalt mixtures made with $20 \%$ of industrial waste containing lignin lead to low thermal susceptibility. Nevertheless, it must be taken into account that after six months of curing time the resilient moduli are higher owing to ageing of the mixture. Furthermore, the thermal susceptibility of mixtures made with $20 \%$ of industrial waste 
is not as low as that at the initial moment. That is, the differences between the control mixture and the mixture made with $20 \%$ of industrial waste are less pronounced as time elapses.

\subsection{Resistance to the permanent deformation}

Figure 10 shows the axial permanent deformation vs. number of load cycles for an AC 22 base $\mathrm{G}$ for the control mixture at its optimum bitumen content (4.5\%) and for an AC 22 base G made with $20 \%$ of industrial waste at its optimum bitumen content $(4.1 \%)$. The permanent deformation resistance was obtained at $30^{\circ} \mathrm{C}$.

This figure includes the results of the initial permanent deformation and the results for mixtures cured during 6 months at room temperature.

Because no specifications have been included in the PG-3 for repeated load axial test results, this test is useful for comparison.

Figure 10 clearly shows that the mixture made with $20 \%$ of industrial waste presents lower permanent deformation than the control mixture $(0 \%)$ at an initial moment. These results are coherent with those obtained in figure 9. In this way, at the initial moment, the stiffness at $30{ }^{\circ} \mathrm{C}$ is higher for mixtures made with $20 \%$ of industrial waste than that for the control mixture. According to this, the deformation will be lower in the stiffer mixture (20\% of industrial waste).

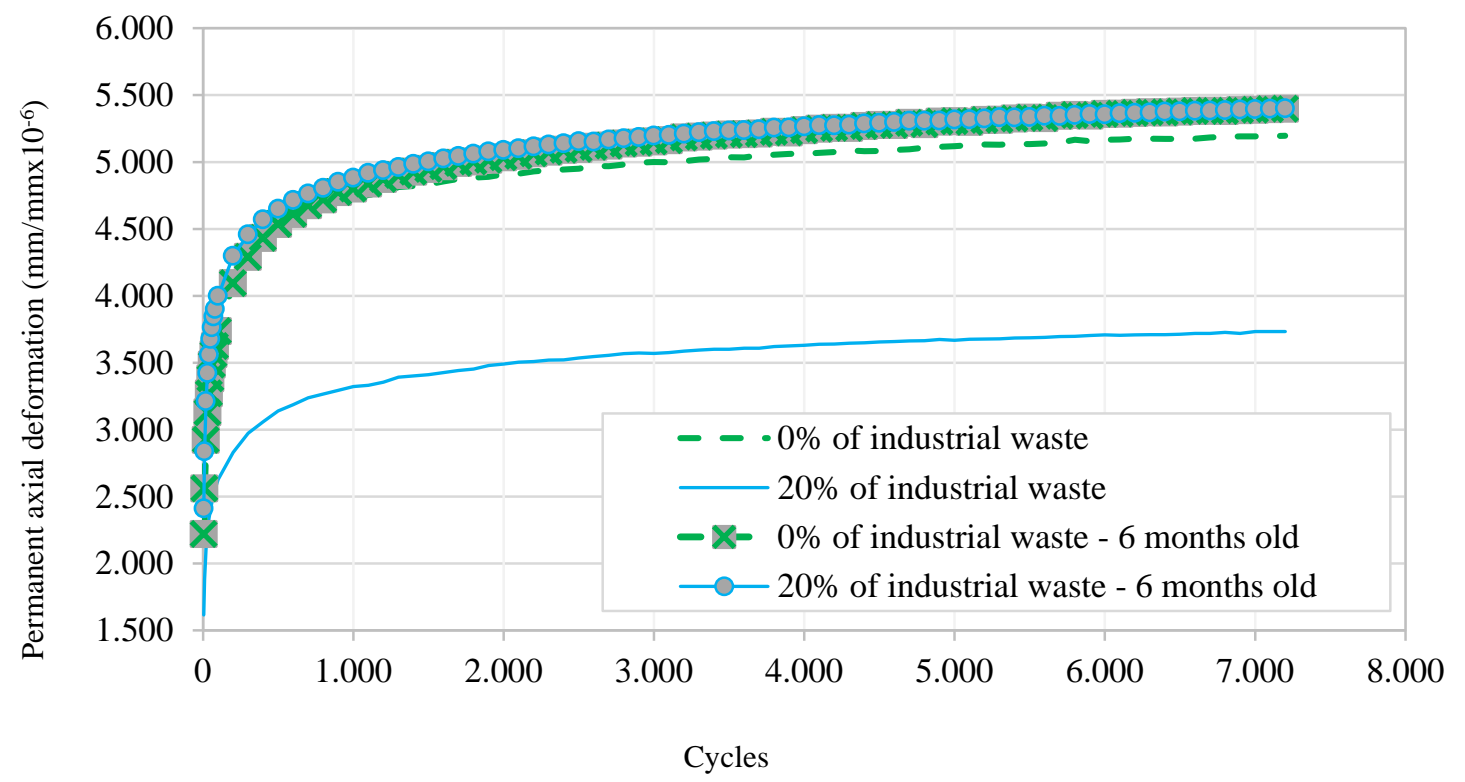

Figure 10. Repeated load axial test results 
Nevertheless, the differences between mixtures made with $0 \%$ and $20 \%$ of industrial waste are not noticeable when 6 months of curing time have passed. Again, the results are coherent with those obtained in figure 9 , because after 6 months of curing time the stiffness at $30{ }^{\circ} \mathrm{C}$ is similar for both mixtures.

\section{Conclusions}

In this research, the feasibility of using industrial waste rich in lignin vegetable biopolymer as a bitumen extender for the production of asphalt mixtures is analysed. The asphalt mixture type AC 22 base $\mathrm{G}$ for base course of road pavements was chosen for this work. The bitumen was mixed with $0 \%$ (control), $5 \%, 10 \%, 20 \%, 40 \%$, and $60 \%$ of industrial waste. The following conclusions were drawn:

- The industrial waste was used without any transformation, thus contributing to economical and cleaner production and to the goal of sustainable construction.

- It is interesting to note that, when the industrial waste is blended with the bitumen, some foaming occurs owing to the sudden warming of the water in contact with the hot bitumen. As the percentage of lignin-containing industrial waste increases, the foaming is more pronounced. Thus, for $40 \%$ and $60 \%$ of industrial waste, it is difficult to operate with the blend owing to the high degree of foam formation. Nevertheless, for lower bitumen contents $(0 \%, 5 \%, 10 \%$, and $20 \%)$, foaming facilitates the mixing operation and leads to a better aggregate-bitumen adhesion.

- When a large amount of industrial waste was used (40\% and $60 \%$ ), some crystallised particles could be observed.

- For all these reasons, the mixture with $60 \%$ of industrial waste showed excessive airvoid content and was discarded.

- The affinity test showed that the use of industrial waste containing lignin biopolymer as extender, in percentages up to $20 \%$, improves the affinity between the bitumen and the aggregate.

- The water resistance test showed that the $0 \%$ (control) and $20 \%$ of industrial waste mixtures displayed the best moisture damage resistance. Thus, the TSR for the control mixture was $82.51 \%$ and that for the mixture produced with $20 \%$ of industrial waste was $81.67 \%$. In both cases, the TSR complied with the Spanish specifications.

- Nevertheless, these results were achieved for $4.5 \%$ and a $4.1 \%$ of bitumen content respectively. That is, the control mixture required a binder (bitumen+industrial waste) content $9.8 \%$ higher than the binder content of the mixture made with $20 \%$ of industrial waste in place of the bitumen. That is, the control mixture consumes $37.2 \%$ more bitumen than the mixture made using $20 \%$ of industrial waste in place of the bitumen. 
- However, the control mixture is adequate for all types of heavy traffic while the mixture made with $20 \%$ of industrial waste is adequate only for medium and low traffic roads.

- At low temperatures, the resilient modulus of the control mixture $(0 \%$ of industrial waste and $4.5 \%$ of binder content) is higher than the resilient modulus of the mixture made with $20 \%$ of industrial waste (and $4.1 \%$ of binder content). The opposite occurs at the highest temperatures. Thus, the thermal susceptibility of the mixtures made with $20 \%$ of industrial waste is lower than that of the control mixture. That is, the control mixture presents higher fatigue resistance at low temperatures and higher resistance to permanent deformation at high temperatures. Nevertheless, the thermal susceptibility differences between the control mixture and the mixture made with $20 \%$ of industrial waste are less pronounced as time elapses.

- The mixtures made with $20 \%$ of industrial waste presented lower permanent deformation than the control mixture $(0 \%)$ at an initial moment. However, after 6 months of curing time, the differences between the mixtures made with $0 \%$ and $20 \%$ of industrial waste are not noticeable.

- For all these reasons, it can be stated that the mixtures made with $20 \%$ of industrial waste showed the best results for medium and low traffic roads (T1 to T4), taking into account the affinity, water resistance, thermal susceptibility, resistance to permanent deformation, sustainability, and economy.

- Nevertheless, the effect of the industrial waste rich in lignin biopolymer in terms of resilient modulus and permanent deformation of the asphalt mixture is particularly noticeable during the first months of the useful life of the mixture.

\section{Acknowledgments}

The authors wish to acknowledge BETANZOS HB for supplying the industrial waste containing lignin biopolymer and REPSOL for generously donating the bitumen used in this investigation.

\section{References}

AENOR. Asociación Española de Normalización y Certificación. UNE-EN 933-8 “Tests for geometrical properties of aggregates. Assessment of fines. Sand equivalent test". Madrid, Spain, 2012b (in Spanish).

AENOR. Asociación Española de Normalización y Certificación. UNE-EN 1097-2 "Tests for mechanical and physical properties of aggregates. Methods for the determination of resistance to fragmentation". Madrid, Spain, 2010a (in Spanish). 
AENOR. Asociación Española de Normalización y Certificación. UNE-EN 12697-11. Asphalt mixtures. Test methods for hot mix asphalt. Determination of the affinity between aggregate and bitumen. Madrid, Spain, 2012 (in Spanish).

AENOR. Asociación Española de Normalización y Certificación. UNE-EN 12697-12 “Asphalt mixtures. Test methods for hot mix asphalt. Determination of the water sensitivity of bituminous specimens". Madrid, Spain, 2009 (in Spanish).

AENOR. Asociación Española de Normalización y Certificación. UNE-EN 12697-8. "Asphalt mixtures. Test methods for hot mix asphalt. Determination of void characteristics of bituminous specimens". Madrid, Spain, 2003 (in Spanish).

AENOR. Asociación Española de Normalización y Certificación. UNE-EN 12697-5. “Asphalt mixtures - Test methods for hot mix asphalt - Part 5: Determination of the maximum density". Madrid, Spain, 2010b (in Spanish).

AENOR. Asociación Española de Normalización y Certificación. UNE-EN 12697-6. “Asphalt mixtures - Test methods for hot mix asphalt - Part 6: Determination of bulk density of bituminous specimen. Madrid, Spain, 2012c (in Spanish).

AENOR. Asociación Española de Normalización y Certificación. UNE-EN 12697-26. Annex C. Asphalt mixtures. Test methods for hot mix asphalt. Stiffness. Madrid, Spain, 2012c (in Spanish).

Ait- Kadi, A., Brahimi, B., \& Bousmina, M. (1996). Polymer blends for enhanced asphalt binders. Polymer Engineering \& Science, 36(12), 1724-1733.

Al-Hadidy, A. I., Yi-Qiu, T., \& Hameed, A. T. (2011). Starch as a modifier for asphalt paving materials. Construction and Building Materials, 25(1), 14-20. https://doi.org/10.1016/j.conbuildmat.2010.06.062

ASTM. American Society of Testing Materials. ASTM D 3625-96. Standard Practice for Effect of Water on Bituminous-Coated Aggregate Using Boiling Water, 2005.

Batista, K. B., Padilha, R. P. L., Castro, T. O., Silva, C. F. S. C., Araújo, M. F. A. S., Leite, L. F. M. and Lins, V. F. C. (2018). High-temperature, low-temperature and weathering aging performance of lignin modified asphalt binders. Industrial Crops and Products, 111, 107-116. https://doi.org/10.1016/j.indcrop.2017.10.010

Boerjan W, Ralph J, Baucher M. 2003. Lignin biosynthesis. Annual Review of Plant Biology, 54: $519-546$.

Boomika, A.; Naveen, M.A., Daniel Richard, J., Mythili, A. and Vetturayasudharsanan, R. (2017). Experimental study on partial replacement of bitumen with lignin and plastic. International Journal of Civil Engineering. Special Issue.

Bourzac, K. (2015). Inner workings: paving with plants. Proceedings of the National Academy of Sciences, 112(38), 11743-11744. 
Brovelli, C., Crispino, M., Pais, J., Pereira, P., Using polymers to improve the rutting resistance of asphalt concrete. Construction and Building Materials 77 (2015) 117-123.

Brovelli, C., Crispino, M., Pais, J., Pereira, P., Assessment on fatigue resistance of modified asphalt concrete incorporating fibers and polymers, ASCE Journal of Materials in Civil Engineering Volume 26, Issue 3 (March 2014), pp 554-558.

Brovelli, C., Hilliou, L., Hemar, Y., Pais, J., Pereira, P., Crispino, M., Rheological characteristics of EVA modified bitumens and their correlations with bitumen concrete properties, Construction and Building Materials 48 (2013) 1202-1208.

Brown, E. R., Kandhal, P. S. and Zhang, J. (2001). Performance testing for hot mix asphalt. National Center for Asphalt Technology Report, (01-05).

BSi. British Standards Institution. 1996. Draft for Development DD 226:1996. Method for determining resistance to permanent deformation of asphalt mixtures subject to unconfined dynamic loading.

Chávez-Sifontes and Domine, M. E. (2013). Lignin, structure and applications: depolymerization methods for obtaining aromatic derivatives of industrial interest. Avances en ciencias e Ingeniería, 4(4) (In Spanish).

Cong, P., Wang, J., Li, K., \& Chen, S. (2012). Physical and rheological properties of asphalt binders containing various antiaging agents. Fuel, 97, 678-684. https://doi.org/10.1016/j.fuel.2012.02.028

Gosselink, R. (2016). Lignin helps the biobased economy move forward. https://weblog.wur.eu/biobased-economy/lignin-helps-the-biobased-economy-moveforward/ (accessed 23 March 2018).

Hataf, N., Ghadir, P., \& Ranjbar, N. (2018). Investigation of soil stabilization using chitosan biopolymer. Journal of Cleaner Production, 170, 1493-1500. https://doi.org/10.1016/j.jclepro.2017.09.256

Hernández, N., Williams, R. C., \& Cochran, E. W. (2014). The battle for the "green" polymer. Different approaches for biopolymer synthesis: bioadvantaged vs. bioreplacement. Organic \& biomolecular chemistry, 12(18). http://dx.doi.org/ 28342849.10.1039/C3OB42339E

Jorgensen, T. (2002). Testing adhesion between bitumen and aggregate with the rolling bottle test and the boiling test. In Proceedings of the 6th International Conference on the Bearing Capacity of Roads and Airfields, Lisbon, Portugal, 24-26 June 2002. (Vol. 2).

Kennedy, T. W., Roberts, F. L. and Anagnos, J. N. (1984). Texas boiling test for evaluating moisture susceptibility of asphalt mixtures (No. FHWA-TX-85-63+ 253-5). Center for Transportation Research, Bureau of Engineering Research, University of Texas at Austin. 
Kim, S. and Coree, B. J. (2005). Evaluation of hot mix asphalt moisture sensitivity using the Nottingham asphalt test equipment (No. IHRB Project TR-483). Iowa State University. Center for Transportation Research and Education.

MFOM, Ministry of Public Works. Article 542 (Asphalt Concrete) of the General Technical Specifications for Road and Bridge Works (PG3) from the Spanish Ministry of Public Works. Madrid, Spain, 2015 (in Spanish).

Pan, T. (2012). A first-principles based chemophysical environment for studying lignins as an asphalt antioxidant. Construction and Building Materials, 36, 654-664. https://doi.org/10.1016/j.conbuildmat.2012.06.012

Qin, X., Shen, A., Guo, Y., Li, Z., \& Lv, Z. (2018). Characterization of asphalt mastics reinforced with basalt fibers. Construction and Building Materials, 159, 508-516. https://doi.org/10.1016/j.conbuildmat.2017.11.012

Solaimanian, M., Harvey, J., Tahmoressi, M. and Tandon, V. (2003). Test methods to predict moisture sensitivity of hot-mix asphalt pavements. In Moisture Sensitivity of Asphalt Pavements-A National Seminar. California Department of Transportation; Federal Highway Administration; National Asphalt Pavement Association; California Asphalt Pavement Alliance; and Transportation Research Board.

Slaghek, T. M., van Vliet, D., Giezen, C. and Haaksman, I. K. (2017). U.S. Patent Application No. $15 / 125,268$.

Sun, D., Lu, T., Xiao, F., Zhu, X. and Sun, G. (2017). Formulation and aging resistance of modified bio-asphalt containing high percentage of waste cooking oil residues. Journal of Cleaner Production, 161, 1203-1214.https://doi.org/10.1016/j.jclepro.2017.06.155

Sundstrom, D. W., Klei, H. E., \& Daubenspeck, T. H. (1983). Use of byproduct lignins as extenders in asphalt. Industrial \& engineering chemistry product research and development, 22(3), 496-500.

Terrel, R. L. (1980). Evaluation of wood lignin as a substitute or extender of asphalt (No. FHWA-RD-80-125 Final Rpt.).

Tu, L. L., Wu, S. P., Liu, G., \& Liu, Q. (2016a). Effect of the Xanthan gum biopolymer on rheological and aging properties of bitumens. In Functional Pavement Design: Proceedings of the 4th Chinese-European Workshop on Functional Pavement Design (4th CEW 2016, Delft, The Netherlands, 29 June-1 July 2016) (p. 301). CRC Press.

Tu, L. L., Wu, S. P., Liu, G., Zhou, X. X., \& Ma, S. K. (2016b). Effect of the Welan Gum Biopolymer on Rheological Properties and Storage Stability of Bitumens. Journal of Testing and Evaluation, 44(6), 2211-2218

Van Vliet, D; Slaghek, T., Giezen, C. and Haaksman, I. Lignin as a green alternative for bitumen. In proceeding of the 6th Eurasphalt \& Eurobitume Congress. Prague, Czech Republic. 1-3 June 2016. 
Vila-Cortavitarte, M., Lastra-González, P., Calzada-Pérez, M. Á., and Indacoechea-Vega, I. (2018). Analysis of the influence of using recycled polystyrene as a substitute for bitumen in the behaviour of asphalt concrete mixtures. Journal of Cleaner Production, 170, 12791287. https://doi.org/10.1016/j.jclepro.2017.09.232

Wageningen University \& Reasearch (2015). On the road to using bio-asphalt. https://www.wur.nl/en/newsarticle/On-the-road-to-using-bioasphalt-.htm (accessed 23 March 2018).

Williams, R. C. (2008). Using lignin as an asphalt antioxidant. Tech Transfer Summaries. 10.

Xie, S., Li, Q., Karki, P., Zhou, F., \& Yuan, J. S. (2017). Lignin as Renewable and Superior Asphalt Binder Modifier. ACS Sustainable Chemistry \& Engineering, 5(4), 2817-2823. 10.1021/acssuschemeng.6b03064

Xu, G., Wang, H., \& Zhu, H. (2017). Rheological properties and anti-aging performance of asphalt binder modified with wood lignin. Construction and Building Materials, 151, 801808. https://doi.org/10.1016/j.conbuildmat.2017.06.151

Yuliestyan, A., García-Morales, M., Moreno, E., Carrera, V., \& Partal, P. (2017). Assessment of modified lignin cationic emulsifier for bitumen emulsions used in road paving. Materials \& Design, 131, 242-251. https://doi.org/10.1016/j.matdes.2017.06.024 